\title{
DETEKSI DINI AFASIA PASIEN STROKE AKUT : ANALYTIC REVIEW
}

\author{
Dwi Febryanto*, Retnaningsih ${ }^{* *}$, Fitria Handayani ${ }^{* * *}$ \\ ${ }^{*}$ Departemen Ilmu Keperawatan, Fakultas Kedokteran, Universitas Diponegoro, Semarang, Indonesia, \\ email:dwifebryanto37@gmail.com \\ **) Divisi Neurologi, Rumah Sakit Kariadi, Fakultas Kedokteran Universitas Diponegoro \\ ${ }^{* * *)}$ Departemen Ilmu Keperawatan, Fakultas Kedokteran Universitas Diponegoro, Semarang, Indonesia, \\ email: fitriaha@yahoo.co.id \\ Coresponding Author : dwifebryanto37@gmail.com
}

\begin{abstract}
Abstrak
Afasia merupakan satu tanda dan gejala pada pasien stroke yang jarang terdeteksi sehingga menyebabkan angka kejadian afasia yang dilaporkan masih rendah. Sebagian besar pasien stroke sudah menggunakan gaya berbicara telegrafis dikarenakan oleh adanya keterlambatan untuk mendeteksi tanda dan gejala afasia. Hal tersebut menyebabkan meningkatnya lama rawat pasien stroke, ketidakstabilan emosi seperti depresi dan berdampak terhadap penurunan kualitas hidup. Alat pengkajian untuk menilai afasia menjadi salah satu faktor keberhasilan deteksi dini. Namun, dari alat pengkajian yang ada tergolong lama dan tidak melaporkan sensitivitas dan spesifisitas sehingga dapat diragukan kesahihannya. Tujuan penelitian ini adalah menemukan sensitifitas dan spesifisitas alat ukur, serta waktu dalam mendeteksi afasia pasien stroke akut. Metode yang digunakan adalah analytic review dengan pencarian pada Pubmed dan Science Direct dengan kata kunci afasia, deteksi dini, dan instrumen skrinning pengkajian afasia. Kriteria inklusi yaitu berbahasa Inggris, full text, tahun 2010-2019, sampel pasien stroke, melaporkan sub tes yang digunakan, waktu tes, serta sensitivitas dan spesifisitas. Hasil yang didapatkan yaitu Language Screening Test (LAST) memiliki sensitivitas 98\% spesifisitas 100\%, Mississippi Aphasia Screening Test (MAST*) memiliki sensitivitas 89\% spesifisitas 80\%, dan Mobile Aphasia Screening Test (MAST) memiliki sensitivitas 90\% dan spesifisitas $73 \%$ dengan rentang waktu antara 2-10 menit. Kesimpulan penelitian ini adalah LAST merupakan instrumen yang paling tinggi sensitivitas dan spesifisitasnya dalam mendeteksi afasia stroke akut serta cepat dalam penilaiannya dengan waktu singkat. Peneliti merekomendasikan LAST dapat diadaptasikan di Indonesia sebagai instrumen deteksi dini afasia stroke akut.
\end{abstract}

Kata kunci : stroke akut, afasia, deteksi dini 
Jurnal Ilmu Keperawatan Medikal Bedah 2 (2), November 2019, 1-51

ISSN 2338-2058 (print), ISSN 2621-2986 (online)

\section{PENDAHULUAN}

Deteksi dini afasia merupakan faktor utama untuk menentukan prognosis pasien, sehingga menjadi lebih awal diketahui untuk pengobatan tepat waktu, meminimalkan biaya dan meningkatkan derajat hidup pasien (Plowman, Hentz, \& Ellis, 2011). Penelitian Poslawsky, Schuurmans, Lindeman, \& Hafsteinsdóttir(2010) menunjukkan 79\% pasien stroke ringan tidak terdeteksi afasia. Kasus stroke di Spanyol 21-38\% mengalami afasia (Berthier, 2005). Berdasarkan diagnosis tenaga kesehatan (Nakes) kasus stroke pada tahun 2013 di Indonesia sebanyak 1.236 .825 orang $(7,0 \%)$, sedangkan berdasarkan gejala stroke sebanyak 2.137.941 orang (12,1\%). Di Propinsi Jawa Tengah sendiri sebesar 7,1\% populasi jika diestimasi berkisar 171.035 orang berdasarkan diagnosa Nakes (Kemenkes RI, 2014). Laporan penelitian yang dilakukan di Manado didapatkan bahwa dari 303 pasien yang didiagnosa stroke non hemoragik yang terdeteksi afasia hanya 36 orang sedangkan pada stroke hemoragik hanya 24 orang mengalami afasia (Purnomo, Sengkey, \& Damopolii, 2016).

Masih rendahnya penemuan afasia ini disebabkan karena tidak adanya instrumen pengkajian khusus perawat (Poslawsky, Schuurmans, Lindeman, \& Hafsteinsdóttir, 2010). Perawat memiliki peran penting dalam mengkaji afasia stroke dengan menggunakan instrumen afasia untuk mendeteksi maupun mengevaluasi kemajuan pasien, karena perawat sering menemukan tanda gejala pasien afasia stroke berupa ketidakmampuan bicara, pelo, dan sulit mengungkap kata sehingga komunikasi terganggu. Perawat mengumpulkan data subjektif dan objektif tersebut kemudian menegakkan diagnosa keperawatan gangguan komunikasi verbal sehingga dapat dilaporkan (Poslawsky, Schuurmans, Lindeman, \& Hafsteinsdóttir, 2010; Thommessen, Thoresen, Bautz-Holter, \& Laake, 2009). Di sisi lain, perawat dapat menjalankan fungsi sebagai advokad untuk membela pasien apabila pasien tidak mendapatkan penanganan yang tepat.

Deteksi dini afasia dengan menggunakan instrumen penilaian adalah paling baik pada waktu golden period (1 sampai 3 bulan) stroke, sebab penemuan afasia stroke pada fase ini dapat segera dilakukan intervensi sedini mungkin sehingga menurunkan kecacatan, mencegah munculnya gaya bicara telegrafis serta menurunkan Long of Stay (LOS) (Iqbal, 2011). Instrumen penilaian afasia seperti Token Tes, Boston Diagnostic Aphasia Examination (BDAE), Minnesota Test for Differential Diagnosis of Aphasia (MTTDDA), Functional Communication Profile (FCP) dikembangkan dalam menilai afasia setelah pasca stroke (Prins \& Maas, 2002). Namun, alat ukur ini memerlukan waktu antara 30 menit sampai 3 jam untuk deteksi afasia dan tidak ada laporan mengenai sensitivitas dan spesifisitasnya, alat ukur ini juga 
sulit dilakukan pada pasien yang tidak toleransi terhadap waktu yang lama yang dapat menimbulkan rasa jenuh pasien (Erdodi \& Roth, 2017; Prins \& Maas, 2002). Berdasarkan hal tersebut, studi ini bertujuan untuk menemukan sensitifitas dan spesifisitas alat ukur yang cepat dalam mendeteksi dini afasia pasien stroke akut.

\section{METODE PENELITIAN}

Terdapat 12 artikel yang diambil dari Pubmed dan Science Direct, 3 dipilih karena memenuhi kriteria inklusi antara lain bahasa Inggris, tahun terbit 2009-2019, teks penuh, subjek yang diteliti adalah pasien stroke, melaporkan sensitifitas, spesifisitas, dan waktu tes. Kata kunci yang digunakan afasia, pengkajian afasia, dan stroke akut. Peneliti mengekstrak data dengan melihat nilai sensitivitas dan spesifisitas dari masing-masing artikel yang menampilkan instrumen pengkajian afasia pada stroke akut. Selain itu, waktu atau lamanya pengkajian menggunakan instrumen, jumlah sampel, onset serangan stroke, sub tes yang digunakan juga dilihat. Sebanyak 12 artikel yang terjaring dari kata kunci yang dipilih, 7 artikel dikeluarkan karena tahun kurang dari 2009, kemudian 5 artikel diidentifikasi, dan 2 artikel dikeluarkan karena subjek yang diteliti adalah pasien demensia dan berbahasa Spanyol, akhirnya 3 artikel yang diambil kemudian dianalisa.

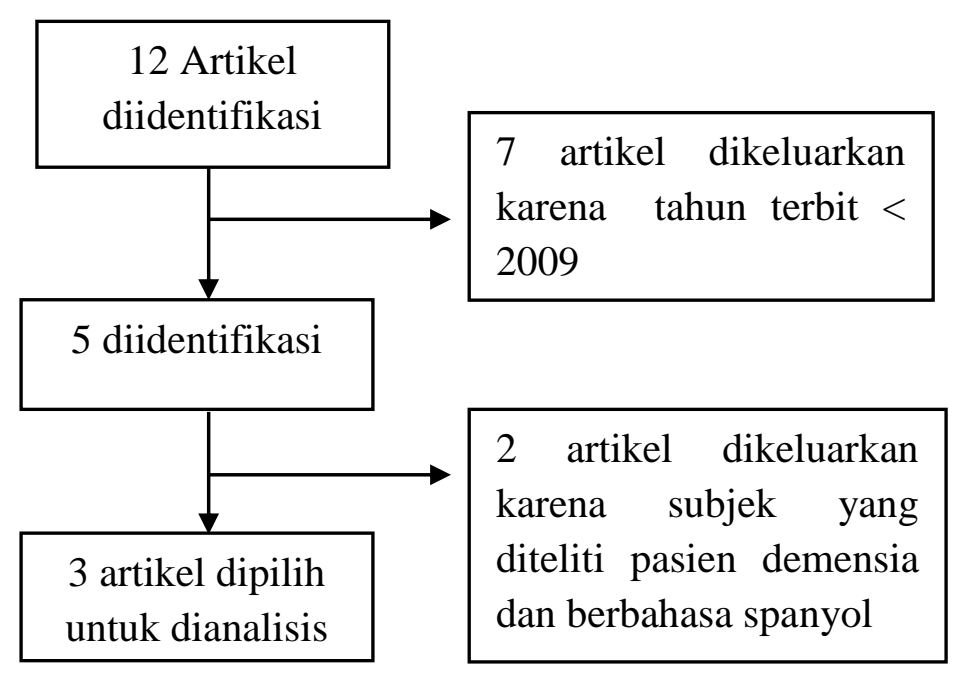

Gambar 1. Alur Seleksi Review Artikel 


\section{HASIL DAN PEMBAHASAN}

Dari 3 artikel yang dipilih untuk dianalisis dilihat mengenai alat ukur yang digunakan, jumlah sampel, onset stroke, sub tes yang digunakan, waktu tes, serta nilai sensitivitas dan spesifisitas. Hasil analisis dari temuan tersebut dapat dilihat pada Tabel 1.

Tabel 1. Hasil Analisis

\begin{tabular}{|c|c|c|c|c|c|c|}
\hline $\begin{array}{c}\text { Screening } \\
\text { Test }\end{array}$ & Sampel & $\begin{array}{l}\text { Onset } \\
\text { Stroke }\end{array}$ & Sub Tes & Waktu Tes & Sensitivitas & Spesifisitas \\
\hline $\begin{array}{l}\text { LAST } \\
\text { Flamand- } \\
\text { Roze, } \\
2011\end{array}$ & 102 & $\begin{array}{l}\text { Tidak } \\
\text { dilaporkan }\end{array}$ & $\begin{array}{l}\text { Menamai, pengulangan, bicara } \\
\text { spontan, } \\
\text { perintah verbal }\end{array}$ & 2 menit & 98 & 100 \\
\hline $\begin{array}{l}\text { MAST** }^{*} \\
\text { Nursi et } \\
\text { al, } 2019\end{array}$ & $\begin{array}{l}50 \\
\text { stroke } \\
\text { akut } \\
\text { dan } 126 \\
\text { relawan } \\
\text { sehat }\end{array}$ & 2-4 hari & $\begin{array}{l}\text { Pasien stroke akut diuji : } \\
\text { kemampuan bahasa ekspresif } \\
\text { dan reseptif } \\
\text { Relawan sehat diuji menamai, } \\
\text { bicara spontan, pengulangan, } \\
\text { mengikuti instruksi dengan } \\
\text { respon ya/tidak, menulis, } \\
\text { pengenalan objek, membaca } \\
\text { dan melaksanakan perintah, } \\
\text { influensi verbal }\end{array}$ & 5-10 menit & 89 & 80 \\
\hline $\begin{array}{l}\text { MAST } \\
\text { Choi, } \\
\text { Park, Ahn, } \\
\text { Soon, \& } \\
\text { Paik, 2015 }\end{array}$ & 60 & 2-8 hari & Ekspresi dan comprehension & 3 menit & 90 & 73 \\
\hline
\end{tabular}

Keterangan :

LAST : Language Screening Test

MAST* : Mississippi Aphasia Screening Test

MAST : Mobile Aphasia Screening Test

Berdasarkan tabel di atas diketahui Language Screening Test (LAST) memiliki nilai sensitivitas $98 \%$ dan spesifisitas 100\%, Mississippi Aphasia Screening Test (MAST*) memiliki nilai sensitivitas 89\% dan spesifisitas 80\%, serta Mobile Aphasia Screening Test (MAST) memiliki nilai sensitivitas $90 \%$ dan spesifisitas $73 \%$ dengan perbedaan rentang waktu di antara ketiganya berkisar 2-10 menit. Hasil ini menunjukkan LAST menjadi instrumen yang paling tinggi nilai sensitivitas dan spesifisitasnya dalam mendeteksi afasia stroke akut serta cepat dalam penilaiannya dengan waktu singkat.

Manfaat deteksi dini adalah mengetahui lebih awal pada seseorang yang memungkinkan terkena suatu penyakit. Deteksi afasia menggunakan penilaian afasia penting 
Jurnal Ilmu Keperawatan Medikal Bedah 2 (2), November 2019, 1-51

ISSN 2338-2058 (print), ISSN 2621-2986 (online)

karena berkontribusi pada masalah bahasa dan kecerdasan, bahasa dan memori jangka pendek, dominasi otak, lateralitas, dan kemampuan kognitif (Kertesz, 2007). Selain itu, hal ini dilakukan untuk perencanaan pengobatan yang tepat waktu sehingga menurunkan depresi pasien afasia stroke, meningkatkan rehabilitasi, menurunkan kematian (Nys, Zandvoort, Worp, Haan, Kort, \& Kappelle, 2005). Di sisi lain, deteksi dini afasia pasca stroke dapat meningkatkan rehabilitasi dengan mengambil keuntungan dari sinergi antara terapi wicara dan perawat saraf (Flamand-Roze et al., 2011). Akibat dari pasien yang terkena afasia stroke tapi belum tertangani, maka akan dapat mengakibatkan beberapa masalah dalam perawatan, antara lain menimbulkan gaya bicara telegram, meningkatnya lama rawat inap, mempengaruhi kesejahteraan pasien, kemandirian, partisipasi sosial, dan kualitas hidup.

Hasil studi sebelumnya oleh Enderby melaporkan bahwa Freanchay Aphasia Screening Test (FAST) juga merupakan instrumen penilaian afasia. FAST mempunyai empat sub tes yaitu berupa pemahaman, ekspresi verbal, tes membaca, dan menulis. Pengujian dilakukan dengan kartu stimulus dua sisi yang menggambarkan adegan di satu sisi dan dan bentuk geometris di sisi lain dan lima kalimat tertulis, FAST juga memiliki nilai sensitivitas $87 \%$ dan spesifisitas $80 \%$ dalam menilai afasia, namun alat ini masih tinggi bias karena masih melibatkan subtes menulis. Selain itu, ditemukan juga bahwa Boston Diagnostic Aphasia Examination (BDAE), Minnesota Test for Differential Diagnosis of Aphasia (MTTDDA), Functional Communication Profile (FCP) dikembangkan dalam menilai afasia paska stroke (Prins \& Maas, 2002). Namun, alat ukur ini memerlukan waktu antara 30 menit sampai 3 jam untuk deteksi afasia dan tidak ada laporan mengenai sensitivitas dan spesifisitasnya. Peneliti menemukan Mississippi Aphasia Screening Test (MAST*) yang diselidiki pada pasien dengan tipe stroke akut pada rata-rata usia 54 tahun. MAST* memiliki rentang skor dari 0-100 dan dilakukan di samping tempat tidur. Penilaian afasia dilakukan oleh terapis dengan menilai saat pasien bicara dan berbahasa pada 50 subjek yang meliputi 29 pasien stroke akut dipilih sebagai responden kelompok intervensi dan dibandingkan dengan 126 pasien stroke sebagai kelompok kontrol sebagai. Dalam penilaiannya tidak dilakukan blind. Nilai sensitivitas masing - masing 89\% dan 80\% dan waktunya 5-10 menit (tabel 1). Instrumen MAST* memiliki sub tes instruksi dengan respon ya/tidak dan tes menulis jika sub tes ini dilibatkan maka pasien hanya menimbulkan anggukan kepala. Kebanyakan dari pasien stroke akut juga mengalami kelumpuhan di salah satu ekstremitas baik tangan maupun kaki, aspek ini perlu juga dipertimbangkan dalam tes menulis dari instrumen, sehingga dalam penilaiannya memiliki bias yang cukup tinggi (Nursi et al., 2019). Di sisi lain, peneliti juga menemukan Mobile Aphasia Febryanto, Retnaningsih, Handayani / Deteksi Dini Afasia Pasien Stroke Akut ...Page 37 of 51 
Jurnal Ilmu Keperawatan Medikal Bedah 2 (2), November 2019, 1-51

ISSN 2338-2058 (print), ISSN 2621-2986 (online)

Screening Test (MAST) yang diselidiki pada pasien dengan tipe stroke iskemik dan hemoragik pada rata-rata usia 54 tahun. Memiliki rentang skor 0-20 dan tidak melaporkan tempat dilakukannya tes. Penilaian afasia dilakukan oleh terapi bicara dan bahasa. Dalam penilaiannya tidak dilaporkan dilakukannya blind. Nilai sensitivitas spesifitasnya masing - masing $90 \%$ dan 73\% serta diproses hanya dalam waktunya 3 menit. Dari 60 subjek penelitian 27 terdeteksi afasia dan 22 tidak terdeteksi. Instrumen ini memiliki subtes pada ekspresi dan pemahaman, walaupun instrumen ini telah dilaporkan bahwa subjek dalam penelitian memiliki onset serangan stroke 2-8 hari diragukan karena kebanyakan pasien stroke yang ditemukan dalam onset waktu tersebut adalah kebanyakan pasien mengalami penurunan kesadaran. Disisi lain instrumen ini tidak dilakukan blind pada saat uji coba sehingga instrumen ini juga memiliki bias yang cukup tinggi (Choi, Park, Ahn, Son, \& Paik, 2015). Temuan lain juga menunjukkan bahwa Language Screening Test (LAST) merupakan instrumen untuk mendeteksi afasia pada pasien stroke akut secara singkat. LAST berupa gambar hitam putih yang disajikan pda halaman lembaran berupa Expresion Index dan Receptive Index. Instrumen ini berfokus pada penamaan gambar, pengulangan kata dan kalimat, berbicara spontan, pemahaman gambar dan mengikuti perintah verbal. Jumlah skor yang diperoleh antara 0-15. LAST masih dalam versi bahasa Inggris sehigga perlu dialih bahasa ke versi Bahasa Indonesia. Pada pemeriksaan ini pasien akan diberikan kartu bergambar yang menghadap ke pasien dan penilaiannya menghadap ke pemeriksa. Total penilaian dari keseluruhan test LAST adalah 15, dikatakan afasia apabila nilai < 15 dan dikatakan tidak afasia apabila nilainya 15. (Flamand-Roze et al., 2011; Flowers, Flamand-Roze, Denier, \& Roze, 2015; Koenig-Bruhin et al., 2016). Nilai validitas dan reliabilitas alat ukur dilihat dari sensitivitas dan spesivitas yaitu LAST memiliki nilai sensitivitas 98 dan Spesifitas 100 dengan rata - rata penggunaan 2 menit dan memiliki bias yang lebih rendah dengan nilai 3 dari total sampel, kriteria inklusi dan Blinding. Tingkat deteksi dini oleh LAST dari 52 pasien afasia yang diuji 51 nya tepat dan sesuai dinilai dengan LAST dan dari 50 pasien stroke dengan tidak afasia yang diuji semuanya dinyatakan negatif afasia. Di sisi lain LAST dalam penilaiannya dilakukan secara buta (blind) sehingga memiliki bias yang lebih rendah dibandingkan dari MAST. Ketiga instrumen tersebut memiliki keterbatasan yaitu tidak bisa digunakan pada pasien buta huruf, tuli dan penurunan kesadaran, sehingga dalam penilaiannya perlu dilakukan uji sebelum dilakukan pemeriksaann afasia (Salter, Jutai, Foley, Hellings, \& Teasell, 2006).

Deteksi dini afasia stroke akut perlu dilakukan dengan menggunakan instrumen yang memiliki validitas dan relibilitas baik. Dimana apabila afasia tidak dideteksi secara dini, maka Febryanto, Retnaningsih, Handayani / Deteksi Dini Afasia Pasien Stroke Akut ...Page 38 of 51 
Jurnal Ilmu Keperawatan Medikal Bedah 2 (2), November 2019, 1-51

ISSN 2338-2058 (print), ISSN 2621-2986 (online)

dapat minumbulkan gaya bicara gramatikal dan menyebabkan meningkatnya lama rawat inap, mempengaruhi kesejahtraan pasien, kemandirian, partisipasi sosial, dan kualitas hidup. Tersedianya alat deteksi afasia stroke akut, bukan berarti masalah terselesaikan, tapi harus di sertai adanya pedoman, SPO tentang deteksi afasia stroke akut, yang saat ini jarang ada di rumah sakit. Pengetahuan perawat mengenai hal ini juga perlu diperhatikan, di mana perawat tahu tentang afasia stroke akut, serta mau dan mampu menggunakan instrumen deteksi afasia.

\section{KESIMPULAN}

Language Screening Test (LAST) adalah instrumen yang paling baik dalam deteksi dini afasia stroke akut dengan pertimbangan cepat dan memiliki sensitivitas yaitu $98 \%$ dan spesifitas $100 \%$ walaupun tidak melaporkan onset serangan stroke. Subtes yang dinilai LAST perlu pertimbangan penilaian kesadaran terlebih dahulu serta tidak memiliki gangguan penglihatan dan pendengaran karena instrumen ini melibatkan audio visual berupa gambar hitam putih dan instruksi verbal dari pemeriksa. Akhir kata peneliti menyadari bahwa instruksi verbal dari LAST masih dalam bahasa Inggris yang berpengaruh pada panjang kalimat, suku kata dan kosa kata sehingga perlu diharmonisasi dan diadaptasikan jika ingin dilakukan di Indonesia. Diharapkan penelitian yang akan datang untuk menyelidiki onset serangan stroke menggunakan LAST dan mengadopsi instrumen ke dalam Bahasa Indonesia.

\section{DAFTAR PUSTAKA}

Berthier, M. L. (2005). Poststroke aphasia epidemiology, pathophysiology and treatment. Drugs \& Aging, 22(2), 163-182. https://doi.org/10.2165/00002512-200522020-00006

Choi, Y.H., Park, H.K., Ahn, K.H., Son, Y.J., \& Paik, N.J. (2015). A telescreening tool to detect aphasia in patients with stroke. Telemedicine and E-Health, 21(9), 729-734. https://doi.org/10.1089/tmj.2014.0207

Erdodi \& Roth, R. (2017). Low scores on BDAE Complex Ideational Material are associated with invalid performance in adults without aphasia. Applied Neuropsychology:Adult,24(3),264-274. https://doi.org/10.1080/23279095.2016.1154856

Flamand-Roze, C., Falissard, B., Roze, E., Maintigneux, L., Beziz, J., Chacon, A., ...Denier, C. (2011). Validation of a new language screening tool for patients with acute stroke:

The Language Screening Test (LAST). Stroke, 42(5)1224-1229. https://doi.org/10.1161/STROKEAHA.110.609503

Flowers, H.L., Flamand-Roze, C., Denier, C., Roze, E., Silver, F.L., Rochon, E., ...Martino, R. (2015). English adaptation, international harmonisation, and normative validation of The Language Screening Test (LAST). Aphasiology Journal, 29(2), 214-236. https://doi.org/10.1080/02687038.2014.965058

Iqbal, A. (2011). The 'Golden Hour' treatment of acute ischemic stroke. Medicine \& Health, 94, 378-379. http://www.rimed.org/medhealthri/2011-12/2011-12-378.pdf

Kemenkes RI. (2014). Pusat data dan informasi Kementerian Kesehatan RI. Febryanto, Retnaningsih, Handayani / Deteksi Dini Afasia Pasien Stroke Akut ...Page 39 of 51 
http//www.depkes.go.id

Kertesz, A. (2007). Is there a need for standardized aphasia tests? Why, how, what and when to test aphasics. Aphasiology Journal, 313-317. https://doi.org/10.1080/02687038808248931

Koenig-Bruhin, M., Vanbellingen, T., Schumacher, R., Pflugshaupt, T., Annoni, J.M., Müri, R.M., ...Nyffeler, T. (2016). Screening for language disorders in stroke:German validation of the Language Screening Test (LAST). Cerebrovascular Disease Extra. (6); 27-31. https://doi.org/10.1159/000445778

Nursi, A., Padrik, M., Nursi, L., Pahkel, M., Virkunen, L., Kuttim-Rips, A., \& Taba, P. (2019). Adaption and validation of the Mississippi aphasia screening test to Estonian speakers with aphasia. Brain and Behavior, 9(1), 1-8. https://doi.org/10.1002/brb3.1188

Nys, G.M.S., Zandvoort, M.J.E.V., Worp, H.B.V.D., Haan, E.H.F.D., Kort, P.L.M.D., \& Kappelle, L.J. (2005). Early depressive symptoms after stroke: neuropsychological correlates and lesion characteristics. Journal of The Neurological Sciences, 228, 27-33. https://doi.org/10.1016/j.jns.2004.09.031

Plowman, E., Hentz, B., \& Ellis, C. (2011). Post-stroke aphasia prognosis: A review of patientrelated and stroke-related factors. Journal of Evaluation in Clinical Practice, 18 (3), 689694. https://doi.org/10.1111/j.1365-2753.2011.01650.x

Poslawsky, I.E., Schuurmans, M.J., Lindeman, E., \& Hafsteinsdóttir, T.B. (2010). A systematic review of nursing rehabilitation of stroke patients with aphasia. Journal of Clinical Nursing, 19 (1-2), 17-32. https://doi.org/10.1111/j.1365-2702.2009.03023.x

Purnomo, A.M., Sengkey, L.S, \& Damopolii, C.A. (2016). Angka kejadian afasia pada stroke di instalasi rehabilitasi medik RSUP Prof. Dr. R. D. Kandou Manado tahun 2015. Jurnal e-Clinic, 2(4),1-6. https://ejournal.unsrat.ac.id/index.php/eclinic/article/view/14346/13917

Prins, R., \& Maas, W. (2002). Afasia deskripsi pemeriksaan dan penanganan. FK. Universitas Indonesia

Salter, K., Jutai, J., Foley, N., Hellings, C., \& Teasell, R. (2006). Identification of aphasia post stroke : A review of screening assessment tools. Brain Injury Journal, 20 (June), 559568. https://doi.org/10.1080/02699050600744087

Thommessen, B., Thoresen, G.E., Bautz-Holter, E., \& Laake, K. (2009). Screening by nurses for aphasia in stroke- the Ullevaal Aphasia Screening (UAS) 21, 110-115 (July). https://doi.org/10.1080/096382899297846 